\title{
探讨财务共享服务模式对企业财务管理的影响
}

\author{
李丹丹 \\ 中核华辰建筑工程有限公司，陕西西安 710000
}

[摘要]在经济发展的过程中经济模式也变得多样化, 其中在企业经营发展过程中财务共享服务模式得到了广泛的应用并发挥 出了重要的作用。财务共享服务模式既拥有原有模式中的优点又对其中的弊端进行了改进与完善, 得到了良好的创新。近些 年来云计算技术、大数据技术被广泛应用，将其应用到企业财务共享服务模式中可以对企业内部财务管理及会计核算工作进 行创新, 保证企业健康稳定发展。

[关键词]财务共享服务模式; 企业财务管理; 影响

DOI：10.33142/mem.v1i2.2157

中图分类号: F275

文献标识码：A

\section{Discussion on the Influence of Financial Sharing Service Mode on Enterprise Financial Management}

LI Dandan

China Nuclear Huachen Construction Engineering Co., Ltd., Xi'an, Shaanxi, 710000, China

\begin{abstract}
In the process of economic development, the economic model has become diversified, in which the financial sharing service model has been widely used and played an important role in the process of enterprise operation and development. The financial sharing service model not only has the advantages of the original model, but also improves and perfects the disadvantages, and gets good innovation. In recent years, cloud computing technology and big data technology have been widely used. The application of cloud computing technology to enterprise financial sharing service mode can innovate the internal financial management and accounting work of enterprises, and ensure the healthy and stable development of enterprises.
\end{abstract}

Keywords: financial shared service model; enterprise financial management; impact

引言

现阶段, 各企业都在进行改革与创新, 企业规模也逐渐扩大, 这样也给财务管理工作带来一定难度, 在进行财务 管理工作时采用财务共享模式可以确保此项工作顺利开展并提升管理水平。在具体的财务管理工作中应保证财务管理 人员具有较高的专业技能并对原有的财务管理模式进行调整与完善, 强化企业各部门间信息交流, 实现会计、核算管 理一体化, 同时可以有效规避财务风险并对财务数据进行有效控制, 使其可以满足现代企业建设需要 ${ }^{[1]}$ 。

\section{1 财务共享服务模式}

\section{1 财务共享服务中心}

在财务共享服务模式中财务管理流程是其中一项基本工作，利用此可以实现一系列服务工作，财务共享服务中心 可以为企业提供更加优质的财务业务服务，并对企业财务信息进行收集与整合，并借助信息化解、互联网技术对企业 财务管理工作进行规范, 从而提升财务工作整体效率并降低企业经营过程中所产生的财务成本, 可以对海量数据信息 进行甄选并实现财务共享服务中心的专业性及个性化服务，为企业决策提供准确的信息依据。

\section{2 财务共享服务模式的主要特点}

1.2 .1 创新性特点

企业财务共享服务模式是在原有企业财务管理模式的基础上发展而来的，其中充分融合了信息化技术与互联网技 术, 属于一种新型的财务管理模式, 可以充分体现出信息化技术、互联网技术在企业财务信息数据管理中的优势, 实 现财务管理信息、数据集中化、统一化处理。财务共享服务模式使用后可以实现对一个工作地点或不同工作地点财务 管理人员的技术及财务管理流程的统一，并可以将隶属企业经济范围所涉及到的信息及数据上传到财务共享系统中， 企业可以在系统中对所需要的数据、信息进行篮选。此外, 企业财务管理人员应用此种模式进行财务管理可以对财务 部门内、外部资源进行整合及重建, 从而形成一种新的经济管理模式。 


\section{2 .2 规范性特点}

企业在采用财务共享服务模式后可以降低整体成本并可以提升财务管理的实际效率，实现财务管理流程统一化、 标准化。可以说在使用财务共享服务模式后可以对企业内部财务管理人员的工作行为进行规范并可以利用其对财务流 程进行规范化管理, 利用此来约束财务管理人员的行为, 从而降低企业整体管理成本。

1.2 .3 服务性及专业性特点

企业在使用财务共享服务模式后一些与企业合作的单位或客户可以通过此模式获得合作项目指标标准及所需要的 时间等信息。企业中的财务管理人员可以通过财务共享服务模式进行内部财务管理工作。财务共享模式中的硬件主要 包括高新技术软件、现代电子通信系统等, 充分体现出此种模式的现代化。同时可以利用此种模式提升企业内部财务 管理人员的专业性，建立起一支专业的财务人才管理团队，这样不仅可以提升企业财务工作水平同时可以为企业决策 提供有效依据, 为企业合作客户提供更加专业的服务 ${ }^{[2]}$ 。

\section{2 财务共享服务模式在企业中应用的优势}

\section{1 实现财务管理成本的节约}

目前, 财务共享服务模式已经得到更多企业的认可与应用, 在引入财务共享服务模式后可以实现企业财务管理成 本的节约。首先, 人员成本的节约。随着信息化技术的不断发展, 企业财务管理人员是财务管理工作的主力军。特别 是在一些大型企业中不仅对财务管理人员的专业性有要求同时还需要财务管理人员可以对各分公司财务工作进行监督 与管理。而在企业不断改革的过程中对财务管理工作也提出了更高的要求, 同时也增加了财务人员的工作量, 对财务 管理人员的需求量也随之增多, 无形中增加了人员成本。但是企业在引入财务共享服务模式后可以减少财务管理人员 使用量, 从而实现人员成本节约目标; 同时在使用财务共享服务模式后可以充分利用信息化技术对财务管理流程进行 优化, 可以在减少财务管理人员的基础上提升整体工作效率。其次, 实现财务管理流程的优化。财务共享服务管理模 式的特点比较明显, 如标准化、统一化、系统性等, 在使用后可以有效规避企业财务管理过程中重复操作等情况, 实 现对管理流程的优化, 从而节省财务管理成本，提升财务管理工作质量。

\section{2 提升财务管理内部控制水平}

将财务共享服务模式应用到企业财务管理工作中既可以对原有的财务管理模式进行优化，又可以将信息化技术、 企业财务管理及质量监督、绩效管理等进行综合管理, 提升财务内部控制水平。首先, 流程控制, 实现系统化。采用 财务共享服务模式后不仅可以实现财务管理工作内容标准化, 同时可以实现对财务预算、审批工作及执行工作、报销 制度、核算流程系统化管理, 使财务管理流程更加清晰, 有效避免系统系错误。另外, 在引入财务共享服务管理模式 后企业可以实现对分公司财务工作的监管, 全面掌控可用财务信息。其次, 提升财务管理工作标准化、流程化, 使企 业财务管理工作更加专业并可以提升企业财务管理人员工作的专业性，得到良好的财务内部控制工作效果。

\section{3 实现财务管理工作效率提升目标}

将财务共享服务模式应用到企业财务管理工作中可以使管理工作更加标准并可以提升企业经济效益, 从而推动企 业有序发展。首先, 财务共享服务模式中的信息化技术可以有效规避传统管理模式中的弊端, 使财务管理工作变得集 约化并可以简化整体管理流程, 实现财务管理工作规范化, 从而保证企业财务管理工作效率。其次, 将财务共享服务 模式应用到企业财务管理工作中可以使其变得更加规范, 同时可以实现对分公司财务工作的同步化管理, 提升财务管 理工作的准确性, 减少重复性工作, 不仅可以提升工作效率并可以实现管理成本的节约。最后, 企业在引入财务共享 服务模式后可以实现对不同工作的控制并可以减少财务管理人员的工作量, 提升工作效率, 使财务管理人员积极参与 到决策及管理工作中来, 为企业构建起科学的战略发展目标, 提升企业整体经济效益 ${ }^{[3]}$ 。

\section{3 财务共享服务模式所带来的影响}

\section{1 财务共享服务模式的积极影响}

企业在进行财务管理工作时采用财务共享服务模式后可以为企业整体运营工作提供保障, 同时可以对企业财务人 员的思想意识进行提升, 保障财务管理水平可以不断提升。企业在采用财务共享服务模式后可以带来更多的积极影响, 将其与日常财务管理工作融合后不仅可以对财务管理流程进行控制还可以控制业务前期所产生的成本，提高财务管理 预算控制效果。在应用财务共享服务模式后可以实现财务数据快速传递及共享, 同时财务审核人员可以利用财务远程 控制系统对财务数据信息进行管理，保证数据传输的安全性与及时性。

财务共享服务模式在企业中应用后可以对原有的财务管理流程进行优化并可以在财务管理工作中对原有的服务系 统进行完善, 同时可以对数传输过程进行规范, 对各种财务信息进行整合, 为企业决策提供全面、准确的信息, 在应 
用财务共享服务模式后可以对企业财务信息进行后期处理，保证后续工作可以顺利开展。

企业在进行财务管理工作时采用财务共享服务模式可以不断提升财务管理工作质量。财务共享服务模式中涉及到 的内容相对较多, 所以在日常管理工作中可以对财务信息进行优化并判定信息的准确性, 保证财务管理工作的规范性, 最大限度的降低因人为因素所导致的偏差, 提高企业财务管理工作实效性。同时在利用财务共享服务模式后可以优化 企业内部及外部控制系统; 财务管理部门应不断强化与各部门间的沟通, 确保所传递信息的准确性并为企业决策工作 提供准确的信息。企业财务管理工作在应用财务共享服务模式后可以实现财务管理信息公开化并可以促进企业全体人 员参与到财务管理工作中, 实现对整体工作过程的监管, 实现财务管理公开化、透明化。目前企业财务管理工作内容 逐渐增多, 这样信息量也变得更多且更加复杂, 同时财务信息也变得更加分散, 给企业财务信息整合带来困难。但是 在采用财务共享服务模式后可以实现对财务信息的集中化管理，提升整体信息处理效果，确保企业各项工作可以顺利 开展。

\section{2 财务共享服务模式的消极影响}

目前, 更多的企业引入了财务共享服务模式, 但是在具体使用过程中一些环节还是存在小的瑕疪。财务共享服务 模式具有一定的不确定性, 在进行财务信息传输过程中要想保证财务信息的准确性应先在财务管理平台中对所要传输 的信息进行处理。但是随着企业财务管理信息量的逐渐增多, 有很大一部分财务信息在向平台传输的过程中需要人员 辅助完成, 这样就无法保证数据信息传输、处理的及时性与准确性。同时如果财务共享服务中心工作效率不高在进行 财务信息处理的过程中会因沟通不及时、协调能力不足、为了减少数据信息处理时间等未按照流程进行处理, 无法体 现出财务共享服务模式在企业财务管理工作中的作用，给后续工作开展带来阻碍。

虽然企业在不断的进行改革，但是还有很多企业中的财务管理人员没有充分认识到财务管理工作的重要性，财务 共享服务模式应用意识不强, 这样在进行实际财务管理工作时会存在漏洞, 无法保证企业财务管理工作效率。还有一 部分企业财务管理人员专业水平不达标, 这样在实际管理工作中无法熟练使用财务共享服务模式, 财务信息处理不及 时情况比较常见, 无法保证企业财务管理工作效率与质量。即使企业应用财务共享服务模式进行财务管理工作但未调 动起工作人员的积极性, 工作人员只是将财务信息上传到财务共享服务平台上, 未做好财务报表核对工作, 给企业整 体发展带来影响。而且还有一部分财务管理人员在工作中过分依赖财务共享服务系统, 财务信息核查不及时, 缺乏全 面性, 无法为企业决策提供准确的信息。在财务管理工作中应用财务共享服务模式后部分管理人员无法对税务风险进 行准确预测, 导致业务管理工作不明确, 财务管理人员与当地税务管理人员未进行及时沟通, 这样就会给企业资金带 来风险, 给企业经营带来不利的影响 ${ }^{[4]}$ 。

\section{4 财务共享服务模式的应用策略}

\section{1 保证前期准备工作的完整性}

财务共享服务模式应用前企业财务管理人员应先建立起完整的流程框架，可见下图。

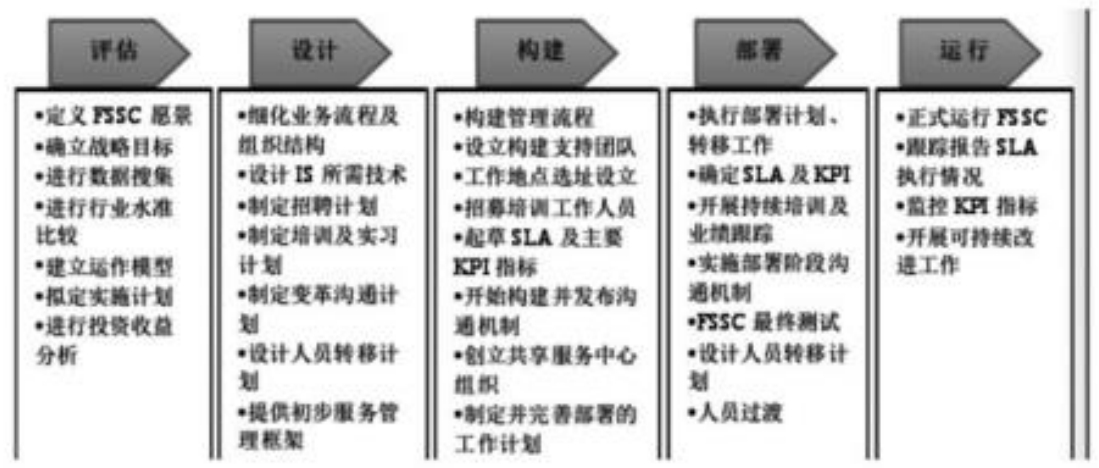

图 1

\section{2 利用财务共享服务模式优化思想工作}

整体优化的过程是在原有财务模式下将新的思想进行添加, 但是企业中的多数员工已经习惯原有模式, 所以在进 行整体优化的过程中就会伤及到一部分人员的利益, 导致员工产生抵触情绪。因此采用财务共享服务模式的前提就是 企业高层管理人员先接受、认可此种模式, 尤其是高层管理人员, 然后逐渐推广到中层管理中进而推动此项工作的实 施。其次，在进行优化的过程中还应与企业基层员工建立好良好的沟通关系，从而确保项目可以顺利实施。 


\section{3 优化财务共享服务模式框架}

在进行财务共享服务模式优化的过程中应先构建起完善的财务共享中心框架。首先, 应对企业原有的财务管理模 式进行全方位的优化，并重点关注财务服务共享平台的优化，从而实现企业各项财务管理工作的分层，如战略财务、 业务财务及共享财务等, 从而提升财务战略决策与业务之间的相互支持, 在保证两者价值的基础上取消财务管理与业 务运营监督的接线, 实现财务管理一体化。其次, 确保企业业务拓展顺利开展并提升其内部管理工作标准化水平, 使 企业财务管理制度更加规范、合理, 从而提升企业财务管理工作水平，保证财务工作质量，从而实现企业财务管理服 务能力提升目标。

\section{4 优化流程性财务共享服务中心}

只有企业财务人员专业知识不断完善并不断提升财务管理水平才能实现对流程性财务共享服务中心进行优化，同 时还应强化档案管理工作并不断对财务信息进行收集、整合, 提升财务人员的学习能力与创新能力, 这样企业领导人 在进行管理的过程中可以实现对财务信息的充分利用。在进行档案管理工作时企业可以将自身情况及下属公司情况进 行总结、归档并采用电子档案管理模式, 从而保证企业财务管理部门信息的完整性。具体的说财务共享服务中心主要 功能模块包括以下方面。业务申请模块在使用后可以将企业中的一些业务前前移并可以在业务实施前就进行控制, 从 而实现对成本的控制。费用报销系统的使用可以实现在线审批及审核并可以保证企业财务信息传输的安全性、时效性。 在进行报销单据传输的过程中可以通过照片形式传输给财务共享服务中心，财务部门认定后可以在网上完成支付报销 费用, 从而节省了报销流程及时间, 提升服务水平。决策支持系统在使用时可以充分利用财务数据实现图表可视化, 将实际产生的数据与预算数据、预算结果及具体经营结果进行对比, 从而对预算过程进行控制并对执行结果进行分析, 从而调整并优化实际生产与预算间的关系 ${ }^{[5]}$ 。

\section{5 强化资金安全管理}

财务共享服务模式的使用可以对企业资金进行集中管理，有效规避了原有财务管理中的资金安全问题，但是在使 用的过程中依然存在安全问题, 这样就需要相关的管理人员不断强化资金安全管理, 在资金管理的过程中应主要以下 方面: 首先应提升财务管理人员资金安全管理意识。一方面在进行财务管理信息输入时应保证输入的准确性。另一方 面负责财务信息化管理的操作人员应各司其职, 明确自身责任并对自身行为进行约束, 按照规范进行操作, 避免因人 为因素给企业带来经济损失。其次构建资金安全管理防护系统。企业在采用财务共享服务模式后可以实现采购管理信 息化, 这样所有的财务信息数据都会处于开放状态, 因此企业应构建防火墙等防护系统, 有效避免不法分子盗取企业 经营信息及转账信息等, 确保资金使用的安全性。最后应不断提升企业财务人员专业能力。目前, 我国财务共享服务 模式还存在一些小的瑕疪, 财务管理信息系统并不完善, 所以为了保证整体系统的完整性及使用效率, 企业还应做好 专业人才的培养工作并建立起完善的人才管理体系。此外, 企业还应根据自身情况构建起人才培养及培训制度, 为专 业人才培养创建良好的环境。

\section{6 控制财务共享服务中心风险}

风险控制工作也是财务共享服务模式优化中的一部分，因此应不断强化风险管理。在优化财务共享服务模式的过 程中企业应先构建起财务风险管理预警系统并与企业实际情况结合后实施财务授权管理模式。利用此来不断强化风险 防范意识并加强主要部门、主要流程的实时预警, 通过财务共享服务中心授权审批控制系统实现对风险的规避。

\section{5 结语}

总的来说, 信息时代的到来也给企业财务管理工作带来新的发展契机, 因此企业应认识到财务管理工作在企业发 展中的作用并积极的引入财务共享服务模式。在与企业财务管理工作结合后充分发挥出财务共享服务模式在财务管理 工作中的作用, 并利用此对原有财务管理模式进行优化, 从而提升企业财务管理工作的时效性, 为企业发展提供动力 ${ }^{[6]}$ 。

\section{[参考文献]}

[1]王悦.浅析财务共享服务中心对企业财务管理的影响 [J]. 财会学习,2019(21) : 39-40.

[2]苏田.财务共享服务中心对建筑企业财务管理的影响 [J]. 时代经贸, 2019 (16) : 20-21.

[3]陈兴.财务共享服务模式对于企业财务管理的影响分析 [J]. 中国乡镇企业会计,2019(03): 111-112.

[4]杨凤琼. 财务共享服务对企业财务管理的影响研究 [J]. 纳税, 2019,13 (04) : 116-119.

[5]栗军. 试析财务共享服务模式对企业财务管理的影响 [J]. 农村经济与科技, 2018, 29(24): 82-83.

[6]黄亚.财务共享服务模式对企业财务管理的影响分析 [J].中外企业家, 2018(31): 60-61.

作者简介: 李丹丹 (1991.4.11-), 女, 陕西科技大学本科, 专业: 数学与应用数学, 当前就职单位: 中核华辰建筑工 程有限公司, 职务: 会计主管, 年限: 5 年。 